\title{
Changes to the micronutrient profile of food served in care homes for older people after the implementation of the Food Standards Agency guidelines
}

\author{
S. Kelly ${ }^{1,4}$, V. Spraggon ${ }^{1,4}$, R. Masters ${ }^{5}$, M. Lees ${ }^{5}$, A. Adamson ${ }^{2,4}$, C. Seal ${ }^{3,4}$, N. Steen ${ }^{2}$ \\ and P. Moynihan ${ }^{1,4}$ \\ ${ }^{1}$ Institute for Ageing and Health, ${ }^{2}$ Institute of Health and Society, ${ }^{3}$ School of Agriculture, Food and Rural Development, \\ ${ }^{4}$ Human Nutrition Research Centre, Newcastle University, Newcastle upon Tyne, NE2 4BW, UK and ${ }^{5}$ Nutrition and Dietetic \\ Service, County Durham and Darlington Community Health Services, Escomb Road, Bishop Auckland, DL14 6AB, UK
}

The Food Standards Agency (FSA) has published nutritional guidance on food served to older people in residential care ${ }^{(1)}$. As part of a wider study that aims to evaluate the barriers and facilitators to implementing the FSA guidelines in care homes and the impact on the food and nutrition provided, the aim of this analysis is to report data on the micronutrient profiles of the menus served in the homes before and after the implementation of the guidelines.

Detailed information on care home menus, including constituent recipes and ingredients was collected from four residential care homes by direct observation of preparation. A dietitian worked with the catering staff to create an amended menu using the FSA guidelines. Home 1 received the most intensive assistance and rigorous intervention, but due to issues with ownership of the new menus cooks took on more responsibility in the subsequent homes. The micronutrients provided by the average daily menu were derived using food composition tables $^{(2)}$ and a purpose written MS Access database. The National Research Ethics Service granted favourable opinion. While three homes made substantial modifications to their menus, dishes served and cooking methods, one home made a few changes (Home 2).

Post intervention, the FSA targets for micronutrients were mainly achieved in Home 1. At baseline, the target for Fe was achieved in three homes; however, following the intervention it was met in all four homes. The sodium content of the menus was not improved by the intervention and the target was only achieved in two homes. The most notable improvement seen was for menu vitamin $\mathrm{C}$ content which increased in all homes. Most homes improved the menu $\mathrm{Mg}, \mathrm{Zn}$ and $\mathrm{K}$ levels, though not all met the guidelines. All homes met the target for folate and riboflavin (both before and after intervention). Values that meet FSA guidelines are highlighted in bold in the Table.

\begin{tabular}{|c|c|c|c|c|c|c|c|c|c|c|}
\hline Mean & & Home 1 & (SE) & Home 2 & (SE) & Home 3 & (SE) & Home 4 & (SE) & FSA guidelines \\
\hline \multirow[t]{2}{*}{ Magnesium (mg/d) } & Before & 209.7 & 7.8 & 226.1 & 9.7 & 259.1 & 13.5 & 211.0 & 10.1 & $>300$ \\
\hline & After & 316.8 & 6.2 & 218.8 & 7.1 & 266.8 & 9.2 & 250.8 & 7.4 & \\
\hline \multirow[t]{2}{*}{ Iron $(\mathrm{mg} / \mathrm{d})$} & Before & 9.6 & 0.7 & 9.0 & 0.3 & 10.0 & 0.6 & 8.1 & 0.3 & $>9$ \\
\hline & After & 13.6 & 0.6 & 9.2 & 0.6 & 9.9 & 0.2 & 10.6 & 0.2 & \\
\hline \multirow[t]{2}{*}{ Zinc (mg/d) } & Before & 8.2 & 1.1 & 8.5 & 1.2 & 7.3 & 0.5 & 5.8 & 0.8 & $>9.5$ \\
\hline & After & 10.7 & 0.8 & 9.1 & 1.2 & 6.8 & 0.3 & 7.8 & 0.3 & \\
\hline \multirow[t]{2}{*}{ Potassium (mg/d) } & Before & 2665.1 & 122.0 & 2919.1 & 117.5 & 3550.2 & 260.5 & 2909.7 & 164.8 & $>3500$ \\
\hline & After & 4184.0 & 95.2 & 2772.2 & 43.5 & 3328.6 & 146.0 & 3377.8 & 145.7 & \\
\hline \multirow[t]{2}{*}{ Sodium (mg/d) } & Before & 2430.6 & 140.1 & 2030.8 & 174.3 & 2933.8 & 228.7 & 1907.1 & 124.7 & $<2352$ \\
\hline & After & 2443.3 & 125.2 & 2106.0 & 189.8 & 2610.7 & 126.6 & 2151.7 & 143.9 & \\
\hline \multirow[t]{2}{*}{ Vit $D(\mu \mathrm{g} / \mathrm{d})$} & Before & 3.11 & 0.47 & 1.76 & 0.26 & 1.86 & 0.15 & 1.84 & 0.39 & 10 (with supplementation) \\
\hline & After & 2.98 & 0.45 & 1.98 & 0.24 & 2.22 & 0.50 & 2.21 & 0.31 & \\
\hline \multirow[t]{2}{*}{ Vit C (mg/d) } & Before & 58.4 & 6.3 & 123.1 & 6.6 & 142.6 & 14.9 & 136.9 & 15.9 & Not specified \\
\hline & After & 181.0 & 8.3 & 144.8 & 15.1 & 174.9 & 6.0 & 190.2 & 17.9 & $\mathrm{RNI}=40$ \\
\hline
\end{tabular}

Intervention to implement the FSA guidelines in care homes positively impacts on the micronutrient content of food provided to older people.

This research was commissioned by the Food Standards Agency, project N14010. The views expressed are those of the authors.

1. Food Standards Agency (2007) Guidance on food served to older people in residential care. http://www.food.gov.uk/multimedia/pdfs/nutguideuk.pdf

2. McCance and Widdowson's The Composition of Foods integrated dataset, see http://www.food.gov.uk/science/dietarysurveys/dietsurveys/ 